\title{
Exploring the socio-cultural impact of Scottish island airports.
}

\author{
BAXTER, G., BLOICE, L. and GRAY, D.
}

2021

This is an Accepted Manuscript of an article published by Edinburgh University Press in Scottish Affairs. The Version of Record is available online at: http://www.euppublishing.com/doi/abs/10.3366/scot.2021.0372. 


\title{
Exploring the socio-cultural impact of Scottish island airports
}

\author{
Graeme Baxter, Lyndsay Bloice and David Gray
}

\begin{abstract}
This paper explores the social importance of small, local airports to Scottish island communities, and the roles that they might play in maintaining cultural identity and a sense of place. It draws upon studies conducted in three communities: Benbecula and Kirkwall, each of which has airports with long histories; and the Isle of Skye, where there have been no air passenger services for over 30 years, but where efforts to reintroduce such services are ongoing. It considers how small, remote airports contribute to social and cultural value in a number of ways, generating benefits beyond those typically reflected in conventional economic analyses. These include: providing 'lifeline' services, particularly in enabling patient access to specialist healthcare; maintaining links with family, friends and the wider diaspora; overcoming perceived remoteness and isolation; acting as socio-cultural arenas in their own right; and being regarded as important symbols of local history, culture and identity.
\end{abstract}

\section{Keywords}

Benbecula; Kirkwall; photo elicitation; Scottish island airports; Skye; socio-cultural impact;

\section{Introduction}

In the final quarter of the twentieth century, a small but influential body of theoretical work emerged, which asserted that airports are bland, superficial locations, devoid of any sense of community, or cultural or emotional attachment. For example, in his 1976 book Place and Placelessness, the geographer Edward Relph argued that airports form part of a 'placeless geography', providing possibilities only for 'commonplace', 'mediocre', and 'shallow' experiences for users (p.79). Almost 20 years later, Relph's observations were echoed by the French anthropologist Marc Augé, who, in his part-fictional ethnology Non-Lieux, translated as Non-Places (Augé, 1995), suggested that airports (and other locations such as railway stations, hotel chains, leisure parks and large retail outlets) are anthropological 'non-places', forming part of a world 'surrendered to solitary individuality, to the fleeting, the temporary and ephemeral' (p.78). Meanwhile, the sociologist Manuel Castells (1996) contended that airport terminals are typically ahistorical and acultural, representing what he termed 'the architecture of nudity' (p.420).

More recently, though, a counterargument has evolved; one that considers the social complexity of airports, and the potential of such spaces to foster emotional bonds, amongst both passengers and workers (e.g., Gottdiener, 2001; Crang, 2002; Adey et al., 2007; Urry et al., 2016). As Merriman (2004,152) suggests:

Airports are spaces where travellers may experience feelings of boredom, frustration, solitariness or dislocation, but these experiences are neither inevitable 
nor limited to such spaces of travel and exchange. Academics must not overlook the complex processes through which such feelings are enacted, and they should pay more attention to the complex histories, geographies and sociologies of such spaces.

Much of this debate has centred on large, international airports. For example, in describing passengers 'suspended in the emptiness of transition', Castells (1996, 421), was discussing Barcelona Airport's new extension, built for the 1992 Olympics; while Gottdiener $(2001,79)$ was considering the likes of Frankfurt, Schiphol (Amsterdam), and Kansai in Japan, when positing the 'emergent placeness' of airport terminals. In contrast, the social impacts of smaller airports, serving more remote, peripheral communities, have received comparatively little attention; and have typically been considered alongside (or as subsidiary to) these airports' more tangible, and measurable, economic impacts.

Certainly, some research has been conducted into the socio-cultural importance of rural airports in Australia (e.g., Ernst \& Young, 2010; Donehue and Baker, 2012; AECOM, 2016), and, to a lesser extent, the United States (e.g., Newkirk and Casavant, 2002; Özcan, 2014) and Norway (Halpern and Bråthen, 2010 \& 2011). In the UK, though, such research is scarce, and appears to have been almost exclusively limited to studies of air services in the Scottish Highlands and Islands. In 2002, SQW explored the economic and social impact of 'no frills' air services in the Highlands, focusing on an easyJet Inverness-Stansted service (cited in York Aviation, 2004, 26); in 2009 an evaluation of the Scottish Air Route Development Fund (RDF) included a summary of the 'social inclusion impacts' of RDF services (Scott Wilson, 2009); while in 2011, Craig conducted an exploratory case study of the socio-economic value of air services to Barra.

This present paper, then, in exploring the social importance of small, local airports to Scottish island communities, and the roles that they might play in maintaining cultural identity and a sense of place, adds to what is a relatively sparse body of empirical work on the subject. More specifically, this paper investigates the socio-cultural impacts of two existing airports: Kirkwall Airport on the Orkney Mainland, and Benbecula Airport in the Outer Hebrides. But it also examines Broadford Airfield, on the Isle of Skye, where scheduled passenger services ceased in 1988, but where ongoing efforts have since been made to reopen the airfield for commercial flights. The research upon which the paper draws was conducted as part of the SPARA (Smart Peripheral and Remote Airports) 2020 project (see http://spara2020.eu), funded by the European Union's Northern Periphery and Arctic Programme, 20142020.

After outlining the data collection methodologies used in the research, this paper will provide brief histories of civil aviation in the three island communities studied. Drawing on two distinct strands of literature, it then presents evidence of actual and potential impacts under seven themes. The paper concludes by considering the implications of the research for airport managers and policy makers, particularly with regard to current efforts to reopen the Broadford Airfield on Skye. 


\section{Methodology}

The key methodology in this study was photo elicitation (see Harper (2002) for an introduction), which was utilised during a series of week-long public photo exhibitions held within the three island communities. These exhibitions consisted of old and contemporary images of, for example: aircraft; terminal buildings; passengers; airport staff; VIP and celebrity visitors; special events taking place at the airports; and airline timetables. The images were obtained from a range of sources, including: local libraries, museums and archives; the airports' own collections; local aviation enthusiasts; and various historical websites. The Kirkwall and Benbecula exhibitions were held within the airport terminals themselves (in October 2015 and October 2016, respectively); while the Skye exhibition was held in August-September 2016, at Broadford Village Hall (see Figure 1) and Portree Community Library. ${ }^{2}$

\section{Figure 1 about here}

At these exhibitions, the researchers engaged with the individuals viewing the images, prompting them to share their memories and experiences of using the airports. These discussions were supplemented by a number of extended face-toface and telephone interviews (and, in Kirkwall, a focus group) with representatives of local community organisations, such as business associations, tourism groups, and third sector bodies. Table 1 provides an overview of the number of participants across the three communities.

\section{Table 1 about here}

In addition to the exhibition-based engagement, an extensive literature search and review was conducted. This literature took a number of forms:

- Academic, government, and professional/trade literature, relating largely to airports or other transport hubs, that has explored the concepts of social and cultural impact, and reported the ways in which such impacts might be identified or measured.

- Newspaper and other press/media coverage, both historical and contemporary, and at national (Scottish) and local levels, which has reported on air passenger services in the Highlands and Islands.

- Historical aviation literature, tracing the evolution of passenger services in the Highlands and Islands. Of particular value here was the online Flight International archive. $^{3}$

- Historical and contemporary documents originating from the key agencies involved with civil aviation in the Highlands and Islands over the last 50 years, 
particularly: the Highland Council; the Highlands and Islands Transport Partnership (HITRANS); Highlands and Islands Enterprise (HIE) and its predecessor, the Highlands and Islands Development Board (HIDB); the Civil Aviation Authority (CAA); and the pre-devolution Scottish Development Department of the Scottish Office. Many of these resources were available online; other, paper-only sources were consulted at the University of Aberdeen and at the National Records of Scotland.

Specifically in relation to the situation on Skye, the researchers also examined the social media accounts of the two key groups involved in campaigning for and against the reintroduction of air passenger services on the island (respectively, FlySkye and SALAD, i.e. Skye and Lochalsh Airport Discussion). In so doing, it was anticipated that the posts would offer additional insights into the perceived socio-cultural benefits, or drawbacks, of reintroduced flights. ${ }^{4}$

\section{Brief histories of civil aviation in the three case study Scottish island communities}

As will be seen in this section of the paper, each of the three case study communities has a long aviation history; although, in the case of Skye, this has been rather fragmented.

\section{Kirkwall Airport}

In many respects, the origins of Kirkwall Airport lie with the exploits of Captain Ernest Edmund 'Ted' Fresson (1891-1963), who is widely regarded as the father of civil aviation in Orkney. A former pilot in the Royal Flying Corps during WWI, Fresson toured Britain in the late-1920s and early-1930s giving aerobatic displays and providing 'joy rides' for paying customers. During one tour to the north of Scotland, Fresson saw an opportunity to begin scheduled air services between Orkney and the Scottish mainland, and in 1933 formed his own airline, Highland Airways Ltd. That same year saw the inauguration of Fresson's Inverness-Kirkwall passenger service, and he was also awarded a contract to carry The Scotsman newspaper on these flights. In 1934, Fresson launched an Aberdeen-Kirkwall service, and started a daily inter-island service in Orkney, calling on demand at Stronsay, Sanday, Westray and North Ronaldsay. In 1934, Highland Airways was also granted the UK's first domestic air mail contract, on the Inverness-Kirkwall service, and was contracted by Orkney County Council to operate the first air ambulance flights in the Northern Isles.

Highland Airways operated out of Wideford Aerodrome, two miles south-east of Kirkwall. Wideford overlooked the site of the current Kirkwall Airport, at Grimsetter, which was originally a WWII military airfield. Built by the Air Ministry, RAF Grimsetter became part of Fighter Command's 14 Group, entrusted with the defence of Britain's naval fleet at Scapa Flow. In 1943, the base was transferred to the Admiralty and became the Royal Naval Air Station, HMS Robin. Following WWII, the airfield reverted to the RAF, and in 1948 became Orkney's main civil airport under the control of the Ministry of Civil Aviation. British European Airways (BEA) began to operate services to and from Aberdeen, Inverness and Shetland; and, in 1967, 
Loganair reintroduced the pre-war Orkney inter-island services. For many years, the main terminal building at Kirkwall consisted of a Nissen hut, which had originally been the wartime administration block. A new terminal building was opened in 1969 .

In 1986, Kirkwall Airport (by then controlled by the CAA) was transferred, along with seven other airports, to Highlands and Islands Airports Limited (HIAL); and in late2001, a new $£ 3.4 \mathrm{~m}$ terminal was opened. Kirkwall currently handles passenger services to Aberdeen, Edinburgh, Glasgow and Inverness on the mainland, and to Sumburgh on Shetland. Kirkwall also continues to be the hub for Orkney's interisland services, which are operated under a Public Service Obligation (PSO) contract. The principal airline flying out of Kirkwall is Loganair, with passenger numbers, in 2018-19, being just under 196,000 (HIAL, 2019). Mail and newspaper flights operate from the airport, as do Marine Scotland's fisheries protection aircraft, and the Northern Lighthouse Board's helicopter.

\section{Benbecula Airport}

Benbecula Airport is situated on the north-west coast of the island, next to Balivanich, and its early history is similar to that of Kirkwall. During the pioneering days of Scottish civil aviation a short-lived airline, Midland \& Scottish Air Ferries (1933-34), surveyed potential landing sites on Benbecula and North and South Uist. But it was another company, Northern \& Scottish Airways, who first developed a grass strip aerodrome at Balivanich, in 1936. This served as part of an extension to their Glasgow Renfrew to Skye service (see below), with on-demand stops at Balivanich. In 1937, Northern \& Scottish merged with Fresson's Highland Airways to form Scottish Airways, which removed Skye from its Hebridean services and included Benbecula as a scheduled stop. At the outbreak of WWII, these services were suspended, but reintroduced on a restricted basis in April 1940. However, in 1941, the airfield was requisitioned by the RAF, and construction began on three hardsurfaced runways. In 1942, 206 Squadron became the first operational unit stationed at RAF Benbecula.

Following WWII, the airport returned to predominantly civic use, with most of the wartime buildings, and two of the three runways, being retained. Scottish Airways continued its Western Isles services before being subsumed as part of BEA in 1947. The Western Isles continued to be served largely by BEA until the mid-1970s, when its successor, British Airways, transferred some of its 'thin' routes with low passenger numbers to Loganair.

Benbecula Airport's military associations continued in the late-1950s, at the height of the Cold War, when it became the control centre for the Royal Artillery's Hebrides rocket range on South Uist. This included the construction of an army base immediately adjacent to the airport, which was further expanded in the late-1960s and early-1970s. The military presence was reduced significantly in the mid-1990s, when control of the rocket range was transferred to the Ministry of Defence's Defence Evaluation and Research Agency (DERA). DERA was privatised in 2001, and the resultant company, QinetiQ, has since retained a presence at the airport. 
In terms of civil aviation, Benbecula Airport, like Kirkwall, became part of HIAL in 1986; and a new terminal building opened in 1993. The airport currently operates three routes, to Glasgow, Inverness and Stornoway, all by Loganair. In 2018-19, passenger numbers at Benbecula were just over 38,000 (HIAL, 2019).

\section{Isle of Skye}

As civil aviation in Scotland grew in the 1930s, Skye became the focus of some attention. After surveying various sites, Northern \& Scottish Airways established an airfield at Glen Brittle, on the south-west coast. This location allowed an uninterrupted (and, in bad weather, relatively clear) approach over the sea from the south-west. A twice-weekly service between Renfrew and Glen Brittle began in December 1935, but was short-lived, ceasing in May 1938. In the immediate postwar period, the reinstatement of a direct Glasgow-Skye service was mooted, but these proposals never came to fruition. It was July 1964 before Skye had its first post-war service to the mainland, when Strathair started an on-demand service between Glasgow, Edinburgh and Skye, with landings made in a field at Skeabost Bridge, near Portree.

The mid-1960s also saw concerted calls for a new airstrip to be built on the island, although its proposed location was the subject of considerable dispute. The Ministry of Aviation favoured a site on the south of the island, at Ashaig, near Broadford, with the British Army Corps of Royal Engineers offering to build the airstrip as part of its Operation Military Aid to the Community (OPMAC) scheme. Skye District Council, however, preferred a site much further north, at Borve, around four miles from Portree. Eventually, the Council agreed that Broadford should be the site, and an airfield was constructed there between 1969-1971, opening officially in April 1972. In July 1972, with financial assistance from the HIDB, Loganair launched SkyeInverness and Skye-Glasgow services. The Inverness service was short-lived, ceasing in 1974. The Glasgow service operated until 1988 (a full seven years before the opening of the Skye Bridge), when, with passenger numbers having dropped by half, and a typical flight being $70 \%$ empty, the Scottish Office withdrew financial assistance because it could 'no longer be justified as a 'lifeline' service' (Scottish Office, 1988).

Although there have been no scheduled services since 1988, the airfield, now owned by Highland Council, is still operational, being used by a flying club, a private seaplane tour company, and the emergency services. Since the late 1990s, however, there have been several proposals to reintroduce passenger services at Broadford, and various consultations and feasibility studies have been conducted. In 2016, in a study commissioned by HIE, ekosgen and Reference Economic Consultants (termed hereafter as 'ekosgen') concluded that a reintroduced service would bring 'significant economic and social benefits' to Skye and its environs (p.70). Their results were incorporated into a business case, produced by RDC Aviation and ARUP (see Highland Council, 2016), and subsequently approved by Highland Council, who, with HITRANS and HIE, aimed to advance the proposals. In April 2018, though, acknowledging the current 'constrained public sector financial environment', a more modest service linking Skye with Glasgow or Edinburgh was proposed, 'on a trial 
basis with the minimum capital investment' (HITRANS, 2018). However, despite Loganair predicting a '70/30 probability' that flights would resume by 2020 (Dalton, 2018), recent reports would suggest that the Scottish Government is unwilling to provide the funding necessary for this trial service to proceed (Glen, 2019a).

\section{Defining socio-cultural impact}

In exploring the potential social and cultural impact of Scottish island airports, one immediate challenge emerges, in that there are no standard definitions of either social impact or cultural impact. With regard to social impact, the lack of a conceptual consensus, across academia, has been highlighted by the likes of Maas and Liket (2011). This problem is already recognised within the Scottish public sector. For example, Communities Challenge Scotland (n.d.), who coordinate the Scottish Government's 'Social Impact Pledge' initiative, observe:

Social Impact can be difficult to define. It is often understood as the effects on people and communities that happen as a result of an action, activity, project, programme or policy.

Within the transport field, specifically, the problem of defining social impact is also acknowledged (e.g., Jones and Lucas, 2012). However, one definition, increasingly recognised in the discipline, is that provided by Geurs et al. $(2009,71)$ :

... social impacts of transport are defined as changes in transport sources that (might) positively or negatively influence the preferences, well-being, behaviour or perception of individuals, groups, social categories and society in general (in the future).

Definitions of cultural impact, meanwhile, are less common, but just as diverse. For example, Sharpley and Stone $(2011,349)$ describe cultural impacts as 'transformations in the processes (values, traditions and norms) through which individuals and societies define themselves and their behaviour'. While Sagnia (2004, 5) suggests that they are 'the consequences to human populations of any public or private policies and actions that significantly change their norms, values, beliefs, practices, institutions as well as the way they live, work, socialize and organise themselves as part of their cultural life.' The conceptual confusion is compounded by the fact that a clear distinction is not always made between social and cultural impacts. Indeed, Partal and Dunphy $(2016,7)$ observe that cultural impact is often discussed as a 'sub-dimension' of social impact; while Sharpley and Stone (2011, 349) prefer to consider them collectively, as 'socio-cultural impacts'.

The definitions above are all rather broad, and lack any great detail on the more specific 'types' of impact encompassed by the overarching terms. In the section that follows, therefore, we consider the socio-cultural impact of Scottish island airports under seven narrower (and often interrelated) themes, drawn from two strands of literature: 1) works on the social impact of cultural services and the arts, particularly that of Matarasso (1997) and Ruiz (2004); and 2) works on the socio-cultural impacts 
of transport services and projects, particularly reviews conducted by Parkhurst and Shergold (2009), Markovich and Lucas (2011), and Jones and Lucas (2012).

\section{The socio-cultural impact of Scottish island airports}

\section{1. 'Lifeline services', accessibility, and connectivity.}

The first of the seven themes discussed is that of lifeline services, accessibility and connectivity. Here, we encounter further conceptual difficulties. While the term 'lifeline services' is used frequently by policymakers, the media, and those in the aviation industry, there appears to be no universally accepted definition. For example, with specific regard to 'lifeline' air services in the Scottish Highlands and Islands, McGregor and Laird (2005) described these as any services to the mainland that allow people to "undertake activities, such as health appointments, leisure activities and business related activities, such as marketing, conferences and training"; while the UK Government (2010), in discussing Orkney and Shetland's 'lifeline' air services, defined these as services where there is:

... no rapid alternative means of transport ... for the services (financial, commercial, professional, advisory, health, etc.) which cannot be provided locally and which are essential for the maintenance of the economic and social fabric of the islands.

More recently, the Covid-19 pandemic has given an additional, more selective perspective on what constitute lifeline air services in the Highlands and Islands; for when 'lockdowns' and travel restrictions have been imposed by the Scottish Government, HIAL has responded by introducing skeleton schedules that provide only 'lifeline and essential services'. These have included 'NHS patient transfer, Royal Mail, the energy sector, and any required emergency flights' (e.g., HIAL, 2020).

At both the Benbecula and Kirkwall photo exhibitions, several participants explicitly described their local air services as 'lifelines', particularly in terms of providing access to healthcare facilities (of which more is discussed later), and in supporting the activities of local businesses and local government employees (including schoolteachers). This was in sharp contrast to the situation encountered on Skye, where such descriptions were rare. Indeed, while the HIE brief for the research conducted by ekosgen $(2016,1)$ expressed a desire to discover the role that rural airports can play in 'providing life-line services', the resultant report did not use the term when presenting the results. Similarly, of almost 2,700 posts on FlySkye's proairfield social media accounts, none used the term when specifically discussing the Skye situation. This contrast may, of course, be simply down to definitional and linguistic factors. However, it is probably fair to say that, during the photo exhibitions in Broadford and Portree, the present authors did sense a different perspective on the essentiality of an air service on Skye. This is no doubt due, at least in part, to the existence of the Skye Bridge. Indeed, in 2007, an HIE and HITRANS evaluation of the socio-economic impacts of the bridge found that it had already reduced perceptions of isolation amongst local residents (p.48), and had had a positive impact 
on the perceived accessibility of healthcare and other essential services (p.77). With the bridge in mind, a number of our Skye exhibition visitors made comparisons with other islands that have no such fixed link to the mainland:

I can understand why a passenger service would be essential for some of the more remote Scottish islands, but with Skye's road bridge and ferry services I don't think an air service is necessary. (Portree participant)

The idea, expressed in the UK Government's (2010) definition, that 'lifeline' air services exist where there are 'no rapid alternative means of transport', was reflected across the three island communities, where there was an acknowledgement that the alternatives, of travelling to the mainland by car, bus and/or ferry, generally involved relatively lengthy journeys. However, opinions on whether or not these alternatives were entirely unattractive or prohibitive were decidedly mixed. Certainly, there were those who felt that travelling by road and/or ferry can be something of a test of endurance:

For speed and convenience, you can't beat the plane. The ferry means travelling takes up your whole day. (Kirkwall participant)

I travel to the mainland regularly for personal and business trips. It can be a really long journey by road, especially if there's been an accident and you have delays and detours. (Portree participant)

Equally, though, there were those who preferred the flexibility, convenience, and comparatively low costs of taking their car to the mainland, particularly if other family members are also travelling:

I occasionally use the airport if I'm travelling on my own. But if the whole family is travelling I'm more likely to take the car on the ferry, because it's cheaper and handier. (Benbecula participant)

The point was also made by several older participants that they were entitled to free concessionary bus travel; so, for example, Skye residents can make the 5-6 hour coach journey to Glasgow for the price of a booking fee only.

A recurring theme in the aviation literature is that of air services in remote regions allowing residents to maintain links with family and friends (e.g., Ernst \& Young, 2010; Halpern and Bråthen, 2010; Smyth et al, 2012); and this was reflected during the Benbecula and Kirkwall exhibitions, where many visitors spoke of the important role of the airport in enabling people to readily return home for family celebrations and important life events, such as marriages and funerals. On Skye, meanwhile, although the ekosgen report (2016) repeatedly referred to the potential for VFR (visiting friends and relatives) air travel, and it was also a relatively regular topic on FlySkye's social media accounts, such trips were mentioned only occasionally by our exhibition visitors, who also tended to qualify their comments by noting that the cost of the air fares would have to be balanced against the urgency of the trip: 
It would actually depend on the price. And also the urgency as well. If there was an emergency down south with my family, and the plane would get me there quicker, then, yeah, it wouldn't matter on the cost. (Portree participant)

Another beneficial aspect of remote airports, occasionally discussed in the literature, is that of enabling greater access to a wider range of leisure and cultural events that take place in larger towns and cities (e.g., Halpern and Bråthen, 2010; AECOM, 2016; Industry High Level Group, 2017). In the SPARA project, while this was a common theme at Donegal Airport (where rock and pop concerts, or big sporting events, in Dublin and Glasgow, are particular attractions), very few of the participants at Benbecula or Kirkwall spoke on this subject. And while the ekosgen report (2016, 60 ) claimed that a reopened Broadford Airfield would 'enhance the potential for residents of all ages to access the Central Belt for leisure, entertainment or cultural events', there was little evidence of a demand for such trips, at least amongst our exhibition visitors.

The international literature on small, peripheral airports has also talked broadly about the benefits of connecting remote communities with the wider world, in, for example, instilling a 'sense of social connectivity' (Donehue and Baker, 2012, 237), and 'overcoming community isolation' (AECOM, 2016, 11). These less tangible concepts were discussed by a number of participants in Benbecula and Kirkwall, with one Orcadian resident observing:

I feel that small airports can generate some of that community confidence... It's definitely making you feel connected to the outside world. People want that.

On Skye, however, participants' opinions on the remoteness of the island, and whether or not the reintroduction of air services could be justified on this basis, were decidedly mixed:

The island feels a bit remote. Having an airport would make it feel less isolated. (Portree participant)

I'm not so sure about the 'reduced isolation' idea in the ekosgen report. The isolation was part of why I moved here. I moved here to get away from places like Glasgow and London. (Broadford participant)

In some respects, these mixed opinions were reflected in an earlier RDC Aviation and ARUP feasibility study, from 2013. In that study, Skye residents believed that onward air connections from Scotland's Central Belt would be an important factor in making their travel choice decisions; but these opinions were not necessarily backed up by evidence that they would actually use a reintroduced air service for connections. RDC and ARUP concluded that 'this may be more related to the perception of making Skye less remote and offering connectivity possibilities, rather than being a vital part of demand' (p.62). This may provide evidence of what Craig $(2011,70)$ describes as the 'existence value' ${ }^{, 5}$ of air services to island communities, 
where the perceived value to local residents lies more in knowing the service exists, rather than in their intended use of the service.

\section{Education and learning}

Another theme, discussed occasionally in the aviation literature, is that of air transport in remote regions enabling better access to education and learning opportunities; in allowing rural residents to attend further and higher education establishments located in larger, more densely populated areas (e.g., York Aviation, 2004; Industry High Level Group, 2017). This aspect of air travel was mentioned by small numbers of participants at both Benbecula and Kirkwall, with some observing that their first memories of their local airport involved themselves, or an older sibling, flying off to begin university on the mainland. With regard to contemporary student air travel, however, those participants with children currently at university tended to note that such trips are relatively rare, due to prohibitive air fares.

On Skye, too, a small number of participants discussed the possibilities of student air travel to Glasgow or Edinburgh, albeit with reservations about the likely fares.

Curiously, though, in considering the reopening of Broadford Airfield, none of the recent feasibility studies appears to have considered the potential for students from Skye to fly to the Central Belt, or elsewhere. This is perhaps particularly surprising, given that Lochaber, Skye and Wester Ross is the area of Scotland with the highest proportion of young people leaving to attend university (HIE, 2015, 2). Instead, the focus has been on people travelling to Skye, to attend the Gaelic College, Sabhal Mòr Ostaig (SMO), at Sleat, described by ekosgen $(2016,54)$ as a 'strong advocate of an introduced air service'. Here, the emphasis is on attracting international conference delegates and, to a lesser extent, international students taking short residency courses, particularly students 'with higher levels of disposable income'. In explaining their focus on incoming educational travel, ekosgen argue that 'a strong SMO equates with a more sustainable community'.

Another potential social benefit of small, remote airports, touched upon only briefly in the aviation literature (Airport Operators Association, 2014, 9), is that airports might be regarded as educational resources in their own right. In both Benbecula and Kirkwall, airport staff told of receiving educational visits from local playgroups, schools and youth organisations, and spoke very positively about their experiences and the feedback received. Staff at Benbecula also spoke of the importance of their work experience arrangements for local schoolchildren, where, each year, four pupils are given a week-long introduction to all aspects of airport work, from fire and rescue, to working in the control tower. We have found no evidence of this type of educational engagement ever having taken place at Broadford, when it was operational; and, in terms of a reintroduced air service, this aspect has not been explored in any of the recent feasibility studies. Given the more modest nature of the most recent iteration of the Skye proposals (HITRANS, 2018), the extent to which staff could undertake any meaningful educational engagement would have to be questioned, at least initially.

\section{Health and well-being}


As was noted earlier, a common theme throughout most of the literature on the social benefits of air transport in remote regions, is that of providing access to medical and healthcare services. This was also a recurring subject throughout the photo exhibitions in Benbecula and Kirkwall, where numerous participants spoke of the need to fly to the mainland for specialist treatments and in emergencies. The point was made repeatedly here that alternative forms of surface transport were too timeconsuming and uncomfortable, particularly for people with chronic or terminal illnesses. Several people spoke knowledgeably, and appreciatively, of their respective health boards' (i.e. NHS Western Isles and NHS Orkney) patient travel arrangements, where, as part of the Highlands and Islands Patient Travel Scheme, the health boards pay most of the patient's travel and accommodation expenses, and sometimes those of an authorised patient escort.

With Skye, however, in considering the potential medical travel benefits of a reinstated Broadford-Glasgow service, the 2016 ekosgen study (pp.57-58) had concluded, rather tentatively, that 'health service delivery in the Skye catchment area could benefit from the introduction of an air service, through improved access to wider healthcare services'; whilst also recognising that a large proportion of the required secondary care provision is currently available within the NHS Highland area, most significantly at Raigmore Hospital in Inverness. ekosgen also forecast only 'modest use' of an air service by NHS staff travelling between Skye and the Central Belt. This apparently limited demand for non-emergency medical transport by air was reflected in the responses from our photo exhibition visitors on Skye, who emphasised that Inverness was the most frequent destination for healthcare-related travel:

Most patient travel from Skye is likely to be to Raigmore in Inverness. Anyway, for 'people of a certain age', a patient minibus leaves Skye daily for Inverness, picking up folk from their homes. (Portree participant)

\section{Local social networks and social capital}

One aspect of peripheral airports, not discussed in the literature, is that of the airport having a social function. During our photo exhibitions, we found that Kirkwall and Benbecula Airports were the venues for numerous serendipitous encounters and social exchanges between family, friends and acquaintances. Indeed, there was frequently a general expectation amongst our participants in these two small and relatively close-knit communities that any visit to their local airport - to fly, to drop off or pick up other passengers, or just to use the airport's café - would result in them bumping in to someone they know. As one Kirkwall participant put it:

I've been out with my wife to see off our son, or nephew, and there'll be somebody else seeing somebody else off. You'll just sit there blethering away until they finally take off. You'll have a newsie - just a catch-up with folk that you might not otherwise have connected with.

Indeed, a number of individuals indicated that, on arriving at the airport, they would make a point of looking around the terminal to see who was present. They also noted 
that the comfortable surroundings and relaxed atmosphere in these airports helps to facilitate and prolong these social exchanges. And while there was a sense amongst our participants that such encounters were becoming less common - due to increased numbers of tourists and inward migrants using the airports - they did appear to reinforce social networks and social capital locally.

On Skye, though, the older exhibition visitors, who had vague recollections of the Broadford terminal in the 1970s and 1980s, provided little evidence to suggest that it ever fulfilled such a role. And, perhaps understandably, the various feasibility and consultancy reports that have appeared over the last 20 years have not really discussed a new airport in terms of it having a social function. With these points in mind, the extent to which any future Skye terminal will facilitate social exchanges is a matter of conjecture, and will very much depend on the building's size, design and facilities, and the degree to which it will be used and visited by the wider Skye and Lochalsh community.

Another socio-cultural aspect receiving little attention in the literature is that of the airport being regarded as a social destination or cultural venue in its own right. At both Benbecula and Kirkwall, the terminal cafés are regularly used by people who are neither flying themselves, nor picking up or dropping off other passengers. In this regard, the cafés were very much seen as social spaces, with patrons being drawn by their accessibility, food quality, prices (at least when compared with those of larger airports), and their general 'environment' and 'atmosphere', particularly in allowing users to view aircraft movements whilst dining. The two airports have also been the venue for various social and cultural events, both indoors and outdoors, including art and craft exhibitions, acoustic musical performances, aviation festivals, and charity fun runs. And while heightened security arrangements, and the time and capacity of airport staff, increasingly challenge these non-aeronautical uses of airport spaces, there certainly appeared to be an appetite to continue with such events. On Skye, meanwhile, opinions were decidedly mixed. Some felt that there would be little potential for any new airport terminal to be regarded as a socio-cultural destination, noting that there were cafés and restaurants 'only five minutes up the road' in Broadford, and that there were already numerous craft shops and artists' studios throughout the island. Others, most notably those involved in the FlySkye campaign group, could envisage 'a modern, bright gateway to Skye' (Facebook, 30 October 2012) that could act as 'some form of events base' (Broadford participant). However, as the most recent proposals for Broadford (HITRANS, 2018) include a $200 \mathrm{~m}^{2}$ modular terminal building, instead of the $720 \mathrm{~m}^{2}$ permanent building originally planned, there would probably be limited scope for any non-utilitarian uses of the airport's space.

\section{Social inclusion/exclusion}

In considering the issues of social inclusion and exclusion, we are again faced with definitional difficulties, with Lucas (2012: 106) noting that, in transport policy and research, 'there is no overarching consensual view about what precisely constitutes social exclusion'. However, one frequently cited paper on this subject is that by Church et al. (2000), who presented a conceptual framework of seven interrelated 
factors that may limit the mobility of socially excluded people. In this present research, two of these seven factors emerged as the most prominent. Firstly, some of the discussion in Kirkwall centred around physical exclusion; although it should be emphasised that this related more to perceived (rather than actual) barriers to disabled passengers using Kirkwall Airport, apparently caused by poor two-way communication between the airport and local disability groups. Secondly, and most significantly, much of the discussion, across all of our case studies, focused on economic exclusion, and the belief that air fares in the Scottish Highlands and Islands are frequently prohibitive. In both Benbecula and Kirkwall, while participants were generally appreciative of the Scottish Government's Air Discount Scheme (see https://www.airdiscountscheme.com/), which provides residents with a 50\% discount on core air fares on certain eligible routes, there was a sense amongst many that the flight costs were still too high. And while it was acknowledged that flights purchased very early could be relatively inexpensive, such discounted seats were perceived as being few in number, and often impractical to book so far in advance.

With Skye, meanwhile, the 2016 RDC and ARUP business case compared the income deprivation level of the Skye catchment area with those of other, existing Highlands and Islands airports, and concluded that 'other things being equal, Skye should have at least a similar demand for air travel, if not greater' (see Highland Council, 2016: 30). However, this was in sharp contrast to the comments of many of the participants in our study. Although two-thirds of our 78 Skye participants were broadly in support of the reintroduction of passenger services from Broadford, very few believed that they would personally use the services; with most of their reservations being related to the affordability of the fares. Several believed that the flights would be affordable only to 'rich tourists' and the more 'well-heeled' Skye residents:

I don't feel it's the normal, local people who would potentially use it.

Everything's going to suit the high-end tourist industry. (Portree participant)

\section{Community empowerment and development}

In the small body of work on the social benefits of remote airports, the existence of air services is sometimes linked to less tangible concepts, such as 'increased local pride' (Özcan, 2014: 115) or a 'stronger community' (Newkirk and Casavant, 2002: 86). Interestingly, in both Kirkwall and Benbecula, participants appeared to demonstrate a real sense of pride in, and 'ownership' of, their local airport:

The airport is a part of Orkney, and it's a part that Orkney can't really be without. So, something this essential just automatically gets acknowledged by the local community, because they know how much, or how often, every one of us needs it. (Kirkwall participant)

On Skye, where, of course, there have been no scheduled air services for over 30 years, and where the current facilities at the Broadford Airfield are decidedly basic, no such sense of pride exists. Instead, it would appear that a sense of injustice and embarrassment surrounds the non-existence of air services, at least amongst some 
sections of the local community. This was most noticeable on FlySkye's social media accounts, where posters regularly pointed enviously to the existence of airports in other Scottish island communities:

Other islands have airports and much faster access to the mainland. (Facebook, 22 January 2016)

We are the largest population in the UK living the furthest from a local airport. (Facebook, 12 April 2016)

\section{Local identity and culture}

As was noted earlier, both Benbecula and Kirkwall airports have long histories: Benbecula first saw scheduled passenger services in 1936; Kirkwall in 1948. Both were also military airfields during WWII. During our photo exhibitions, participants in both communities spoke knowledgeably about the history and development of their local airport. These accounts were frequently intertwined with very personal memories of the physical fabric of the airports, and of their air travel experiences, leading to a sense that the airports were inextricably linked to local identity. For example, older residents in both communities remembered the waiting rooms in the old wartime buildings, complete with wicker chairs, stovepipe fire and open brick fireplace. Other, slightly younger Kirkwall residents spoke of a childhood habit of playing with the luggage belt's wooden rollers in the subsequent terminal building (1969-2001); and also of a time when they could walk around, unhindered, to the apron side of the terminal, to watch the planes taking off and landing. Older Benbecula residents, meanwhile, spoke of the runways there having been used for roller skating, horse riding, and driving lessons. Participants in both communities also spoke of the importance of the airport as a local employer, and recalled various family members and friends (sometimes featured in the photographs) who had worked there.

In Skye, only a small proportion of our participants had personal memories of the Broadford Airfield, from when it was operational between 1972 and 1988. Some spoke of the 'Spartan' conditions at the prefabricated terminal building in its earliest days, with no refreshment facilities, no public telephone, and no connecting bus service. Others remembered their embarrassment on being personally (and publicly) weighed on stand-on scales at the check-in desk. Some looked back fondly on an era when the aircraft's flight deck was usually visible and accessible from the passenger cabin, and where passengers could engage in conversations with the pilot. And some described their flight experiences, on particularly windy days, as 'real wing and a prayer stuff'. In Broadford and Portree, then, while perhaps not as keenly felt as in Benbecula and Kirkwall, Skye's fragmented aviation history did appear to have instilled a sense of local identity among at least some of our participants.

In Kirkwall, this link between their airport and local history, culture and identity is reflected in the design, décor and content of the terminal building, which includes several items of memorabilia that illustrate Orkney's aeronautical past. Indeed, when the current terminal was being constructed, in 2001, conscious efforts were made to 
ensure that its interior reflected Orcadian heritage and culture. With input from a working group comprising representatives of HIAL, Orkney Islands Council, Orkney Enterprise, and the Orkney Tourist Board, local artists were commissioned to produce a range of artwork that illustrates Orkney's history, landmarks, scenery and wildlife. This included the installation of large Scandinavian runic text above the main entrance, reading 'krimsitir', which represents the airport's original name of Grimsetter. As one former working group member explained, this was aimed at ensuring that 'the minute you got off the plane, you knew you'd arrived in Orkney'. Many of our exhibition visitors spoke warmly of this design approach, with one describing Kirkwall as 'the loveliest airport in Scotland'. Benbecula Airport also contains some aeronautical memorabilia, and some local artwork - most notably a piece called 'Fichead Eun' ('Twenty Birds') created by the Uist and Barra Children's Parliament, and a painting depicting the 'Our Lady of the Isles' sculpture on South Uist - although these were not installed as part of any overarching design strategy.

On Skye, meanwhile, our participants generally responded positively when asked if the development of any new terminal building at Broadford should adopt an approach similar to that in Kirkwall. Some suggestions included a mural depicting Skye, similar to one located at the Fingal Centre in Portree; and 'something Skye themed, reflective of the mountains and the shore'. Interestingly, designs reflecting the Cuillin mountain range formed part of a student project, conducted in conjunction with the FlySkye campaign. Here, architectural technology students from the University of the Highlands and Islands produced designs for a potential new terminal building, which took 'full account of the local environment and built heritage', and incorporated a tetrahedral roof that 'echoes the shape of the Cuillin' (see Restan, 2014). Indeed, in many respects, the students' designs appear more ambitious and sophisticated than any put forward by those formally tasked with progressing the proposals; where recognition of local cultural heritage seems to have been limited to the suggested inclusion of 'Gaelic promotion material' (Highland Council, 2016: section 6.6). In any case, the smaller modular building, proposed most recently for Broadford (HITRANS, 2018), will doubtlessly place restrictions on what might be done, in terms of the terminal's design.

The relationship between airports, air travel and local natura/ heritage was also mentioned by some participants, whose comments related largely to the views of local landscapes that can be obtained from the air:

On a clear day, the scenery, especially all the lochs, is spectacular from the air. (Benbecula participant)

The potential for picturesque approaches and landings at Broadford was also highlighted by the FlySkye campaign, who argued that: 'The road journey to Skye and Lochalsh may be stunning, but the flight to Skye would be a very different, magical experience' (Facebook, 30 October 2013). In contrast, though, SALAD have expressed concerns over the impact of any runway extension ${ }^{6}$ on the 'Pulpit Rock' area (an ancient site of worship) to the west of the Broadford airfield (Macaulay, 2019); and have been angered by recent tree felling in the vicinity, particularly of the 'bell tree', on which a bell used to be hung to call people to worship (Glen, 2019b). 


\section{Conclusions}

This paper has explored the actual and potential socio-cultural impact of small airports in Scottish island communities. In doing so, it drew upon studies of three communities: two (Benbecula and Kirkwall) with existing, long-standing airports; and a third (Skye), where there have been no air passenger services for over 30 years, but where efforts to reintroduce such services are ongoing.

The research has revealed that Benbecula and Kirkwall airports contribute to social and cultural value in a number of ways, generating benefits beyond those typically reflected in conventional economic analyses. They provide 'lifeline' services, particularly in enabling patient access to specialist healthcare. They allow residents to maintain links with family and friends on the Scottish mainland, albeit with some reservations about prohibitive fare structures. And they help to overcome perceptions of isolation, in providing a connection with the 'outside world'. Both airports also act as socio-cultural arenas in their own right, being venues for numerous serendipitous encounters and social exchanges, and, occasionally, for organised artistic and cultural events. Our research participants in Benbecula and Kirkwall spoke knowledgeably about the history and development of their local airports, and recalled very personal memories of the terminal buildings and their air travel experiences. These stories appeared to invoke a real sense of pride in, and connection with, their local airports, highlighting their role as important facets of local identity and culture.

On Skye, meanwhile, the fragmented history of civil aviation on the island has meant that the relationship between the Broadford Airfield and local identity is perhaps less keenly felt. Opinions were decidedly mixed on the perceived remoteness of Skye, and on the extent to which the increased connectivity afforded by a reintroduced air service might help to overcome any feelings of isolation. And while two-thirds of our Skye participants were broadly supportive of the reintroduction of flights from Broadford, relatively few indicated that they would personally use these services. Citing concerns about the potential affordability of the fares, they instead suggested that only tourists and more affluent local residents would be in a position to use the air services. There was little evidence of the previous terminal at Broadford having acted as a socio-cultural arena, and opinions were mixed on the potential of any new building to fulfil such a role. In this last regard, the various stakeholders involved in progressing plans for a new airport at Broadford should remain conscious that the more modest facilities outlined in their most recent proposal are likely to impair the generation of the various socio-cultural benefits that are currently enjoyed by airports in other Scottish island communities. 


\section{Notes}

1. Built to replace an existing Kyle of Lochalsh-Kyelakin ferry service, the Skye Bridge was, controversially, the first major Private Finance Initiative project in Scotland. On opening, its tolls made it one of the most expensive bridge crossings in Europe (McQuaid and Greig, 2007). In 2004, the bridge was taken back into public ownership by the Scottish Executive, and the tolls were scrapped. In 2019, an average of almost 5,000 vehicles crossed the bridge each day (Amos, 2020).

2. In the cross-national SPARA 2020 project, exhibitions were also held at Donegal Airport in Ireland, and Sundsvall-Timrå Airport in Sweden.

\section{Previously available at https://www.flightglobal.com/products/flight-} international/archive/, but unavailable at the time of writing (June 2020).

4. Although it should be noted that, by July 2018, FlySkye's social media accounts had closed. SALAD's Facebook account can be found at https://www.facebook.com/groups/573074446420800/

5. The concept of 'existence value' is generally attributed to Krutilla, who applied it to natural resources, such as landscapes, ecosystems, or threatened species. See Krutilla (1967).

6. The RDC Aviation and ARUP 2016 business case, and their 2013 feasibility study, both built on previous (2007) work by Mott MacDonald. In the Mott MacDonald study, three of the four options explored would have required the existing runway to be extended, both to the west and to the east. It drew on a 2005 environmental impact assessment, conducted by Halcrow, which had highlighted a site of special scientific interest to the north of the airfield, an important otter habitat to the east, and an ancient burial ground and current cemetery to the west; although it was concluded that, in most cases, these impacts could be satisfactorily mitigated (see HITRANS, 2007). In the event, however, the approved business case was based on the runway remaining at its existing length, of $771 \mathrm{~m}$ (Highland Council, 2016).

\section{References}

Adey, P., Budd, L., and Hubbard, P. (2007). Flying lessons: exploring the social and cultural geographies of global air travel. Progress in Human Geography, vol. 31, 773791.

AECOM (2016). Community Value of Regional Airports in South Australia. Adelaide: AECOM Australia.

Airport Operators Association (2014). Airports in the Community: The Story of How UK Airports Help Their Local Communities. https://www.aoa.org.uk/wp- 
content/uploads/2014/06/AOA-AIRPORTS-IN-THE-COMMUNITY.pdf [Accessed 9 June 2020]

Amos, I. (2020). Over the sea to Skye: island life after 25 years with the bridge. Scotsman, 11 October. https://www.scotsman.com/news/people/over-sea-skyeisland-life-after-25-years-bridge-2999203 [Accessed 8 January 2021]

Augé, M. (1995). Non-Places: Introduction to an Anthropology of Supermodernity. Translated by John Howe. London: Verso.

Castells, M. (1996). The Information Age: Economy, Society and Culture. Volume 1: The Rise of the Network Society. Oxford: Blackwell.

Church, A., Frost, M. and Sullivan, K. (2000). Transport in social exclusion in London. Transport Policy, vol. 7, 195-205.

Communities Channel Scotland (n.d.). What is Social Impact?

http://www.communityscot.org.uk/social-impact-pledge/what-social-impact/

[Accessed 3 June 2020]

Craig, R.H. (2011). The value of the air bridge to the Islands. Scottish Geographical Journal, vol. 127, 61-78.

Crang, M. (2002). Commentary. Between places: producing hubs, flows, and networks. Environment and Planning A, vol. 34, 569-574.

Dalton, A. (2018). Flights to Isle of Skye 'likely to resume'. Scotsman, 22 June. https://www.scotsman.com/news-2-15012/transport/flights-to-isle-of-skye-likely-toresume-1-4758187 [Accessed 3 June 2020]

Donehue, P. and Baker, D. (2012). Remote, rural, and regional airports in Australia. Transport Policy, vol. 24, 232-9.

ekosgen and Reference Economic Consultants (2016). Economic and Social Benefits of Proposed Air Services at Skye Airport. https://www.hie.co.uk/researchand-reports/our-reports/2016/january/29/skye-air-services-study-2016/ [Accessed 3 June 2020]

Ernst \& Young (2010). Evaluation of Regional Aviation Developments Under the Regional Infrastructure Development Fund. Melbourne: Ernst \& Young Australia.

Glen, L. (2019a). Plan for flights grounded. Press and Journal, 3 June, p.5.

Glen, L. (2019b). Skye tree chopping 'thin end of wedge' for airport objectors. Press and Journal, 9 March, p.5.

Gottdiener, M. (2001). Life in the Air: Surviving the New Culture of Air Travel. Lanham, MD: Rowman \& Littlefield. 
Geurs, K.T., Boon, W. and Van Wee, B. (2009). Social impacts of transport: literature review and the state of the practice of transport appraisal in the Netherlands and the United Kingdom. Transport Reviews, vol. 29, pp.69-90.

Halpern, N. and Bråthen, S. (2010). Catalytic Impact of Airports in Norway. https://evalueringsportalen.no/evaluering/catalytic-impact-of-airports-in-norway [Accessed 8 June 2020]

Halpern, N. and Bråthen, S. (2011). Impact of airports on regional accessibility and social development. Journal of Transport Geography, vol. 19, 1145-54.

Harper, D. (2002). Talking about pictures: a case for photo elicitation. Visual Studies, vol. 17, 13-26.

HIAL (2019). Annual Report \& Financial Statement, 1 April 2018 - 31 March 2019. https://www.hial.co.uk/wp-content/uploads/2019/08/HIAL-Annual-Report-andFinancial-Statement-201819.pdf [Accessed 3 June 2020]

HIAL (2020). HIAL airports remain open for vital travel links during current restrictions. https://www.hial.co.uk/whats-hot/hial-airports-remain-open-for-vitaltravel-links-during-current-restrictions/ [Accessed 7 January 2021]

HIE (2015). Our Next Generation: Young People in Lochaber, Skye and Wester Ross: Attitudes and Aspirations.

https://www.hie.co.uk/media/3117/youngpluspeopleplusinpluslochaberplusskyeplusa ndpluswesterplusross plusattitudesplusandplusaspirations.pdf [Accessed 9 June 2020]

HIE and HITRANS (2007). Evaluation of the Economic and Social Impacts of the Skye Bridge.

https://hitrans.org.uk/Documents/Evaluation of the Economic and Social Impacts of the Skye Bridge.pdf [Accessed 8 January 2021]

Highland Council (2016). Skye Air Services Business Case 2016.

https://www.highland.gov.uk/download/meetings/id/71139/item 14 skye air service s business case 2016 [Accessed 3 June 2020).

HITRANS (2007). Broadford Airport, Skye: Background Note for Meeting with Civil Aviation Authority.

https://hitrans.org.uk/Documents/Broadford Airport CAA Report.pdf [Accessed 11 January 2021]

HITRANS (2018). Report to Partnership Meeting of 20 April 2018. Research and Strategy Delivery. Skye Air Service Short Life Working Group - Delivery of Air Services at a Minimum Cost. https://hitrans.org.uk/Documents/ltem 15 -

Skye Air Service Short Life Working Group.pdf [Accessed 3 June 2020] 
Industry High Level Group (2017). Aviation Benefits 2017.

https://www.icao.int/sustainability/Documents/AVIATION-BENEFITS-2017-web.pdf

[Accessed 4 June 2020]

Jones, P. and Lucas, P. (2012). The social consequences of transport decisionmaking: clarifying concepts, synthesising knowledge and assessing implications. Journal of Transport Geography, vol. 21, 4-16.

Krutilla, J.V. (1967). Conservation reconsidered. The American Economic Review, vol. $57,777-86$

Lucas, K. (2012). Transport and social exclusion: where are they now? Transport Policy, vol. 20, 105-13.

Maas, K. and Liket, K. (2011). Social impact measurement: classification of methods. In R. L. Burritt et al. (eds.) Environmental Management Accounting and Supply Chain Management, 171-202. Dordrecht: Springer.

Macaulay, S. (2019). Call for Skye air services to be grounded. Press and Journal, 9 January, p.5.

Markovich, J. and Lucas, K. (2011). The Social and Distributional Impacts of Transport: a Literature Review. Transport Studies Unit Working Paper No. 1055. https://www.tsu.ox.ac.uk/pubs/1055-markovich-lucas.pdf [Accessed 3 June 2020]

Matarasso, F. (1997). Use or Ornament? The Social Impact of Participation in the Arts. http://www.artshealthresources.org.uk/wp-content/uploads/2017/01/1997Matarasso-Use-or-Ornament-The-Social-Impact-of-Participation-in-the-Arts-1.pdf [Accessed 3 June 2020]

McGregor, A. and Laird, J. (2005). Economic Benefits of Improvements to Infrequent Lifeline Services: a Case Study of Air Services in the Highlands and Islands. Paper presented at the Scottish Transport Applications and Research Conference, Glasgow, 26 April. http://www.starconference.org.uk/star/2005/anne mcgregor.pdf [Accessed 3 June 2020]

McQuaid, R.W. and Greig, M. (2007). The bridge to Skye, Scotland. In G. Baldacchino (ed.) Bridging Islands: the Impact of "Fixed Links", 185-202. Charlottetown, PEl: Acorn Press.

Merriman, P. (2004). Driving places: Marc Augé, non-places, and the geographies of England's M1 motorway. Theory, Culture \& Society, vol. 21, 145-167.

Newkirk, J. and Casavant, K. (2002). Functions and Benefits of Rural Airports in Washington. https://www.wsdot.wa.gov/Research/Reports/500/557.1.htm [Accessed 8 June 2020] 
Özkan, I.Ç. (2014). A community evaluation of Essential Air Services. Journal of Air Transport Management, vol. 36, 110-9.

Parkhurst, G. and Shergold, I. (2009). Literature Review: the Treatment of Social and Distributional Impacts in Appraisal and Evaluation. https://uwerepository.worktribe.com/output/997344 [Accessed 3 June 2020]

Partal, A. and Dunphy, K. (2016). Cultural impact assessment: a systematic literature review of current methods and practice around the world. Impact Assessment and Project Appraisal, vol. 34, 1-13.

RDC Aviation and ARUP (2013). Skye Air Services Feasibility Study: Final Issue. https://www.hie.co.uk/media/3193/skyeairservicesstudyreport8mar2013.pdf [Accessed 4 June 2020]

Relph, E. (1976). Place and Placelessness. London: Pion Limited.

Restan, S. (2014). Mountains inspire students to fly high for Skye airport. Press and Journal, 15 January 2014, 4.

Ruiz, J. (2004). A Literature Review of the Evidence Base for Culture, the Arts and Sport Policy. https://www.artshealthresources.org.uk/docs/a-literature-review-of-theevidence-base-for-culture-the-arts-and-sport-policy/ [Accessed 3 June 2020]

Sagnia, B.K. (2004). Framework for Cultural Impact Assessment. https://www.dmeforpeace.org/resource/framework-for-cultural-impact-assessment/ [Accessed 3 June 2020]

Scott Wilson (2009). Evaluation of the Scottish Air Route Development Fund. http://www.evaluationsonline.org.uk/evaluations/Search.do?ui=basic\&action=show\&i $\underline{d=384}$ [Accessed 8 June 2020]

Scottish Office (1988). Glasgow-Skye Air Subsidy Withdrawn. News release, 9 March.

Sharpley, R. and Stone, P.R. (2011). Socio-cultural impacts of events: meanings, authorized transgression and social capital. In S. J. Page and J. Connell, J. (eds.), The Routledge Handbook of Events, 347-61. London: Routledge.

Smyth, A., Christodoulou, G., Dennis, N., Al-Azzai, M. and Campbell, J. (2012). Is air transport a necessity for social inclusion and economic development? Journal of Air Transport Management, vol. 22, 53-9.

United Kingdom Government (2010). Public Service Compensation for Air Links to the Islands. Previously available at https://ec.europa.eu/competition/consultations/2010 sgei/uk 1 en.pdf [Last accessed 26 July 2018] 
Urry, J., Elliott, A., Radford, D., and Pitt, N. (2016). Globalisations utopia? On airport atmospherics. Emotion, Space and Society, Vol. 19, 113-20.

York Aviation (2004). The Social and Economic Impact of Airports in Europe.

http://temis.documentation.developpement-durable.gouv.fr/docs/Temis/0017/Temis0017789/12209.pdf [Accessed 8 June 2020] 


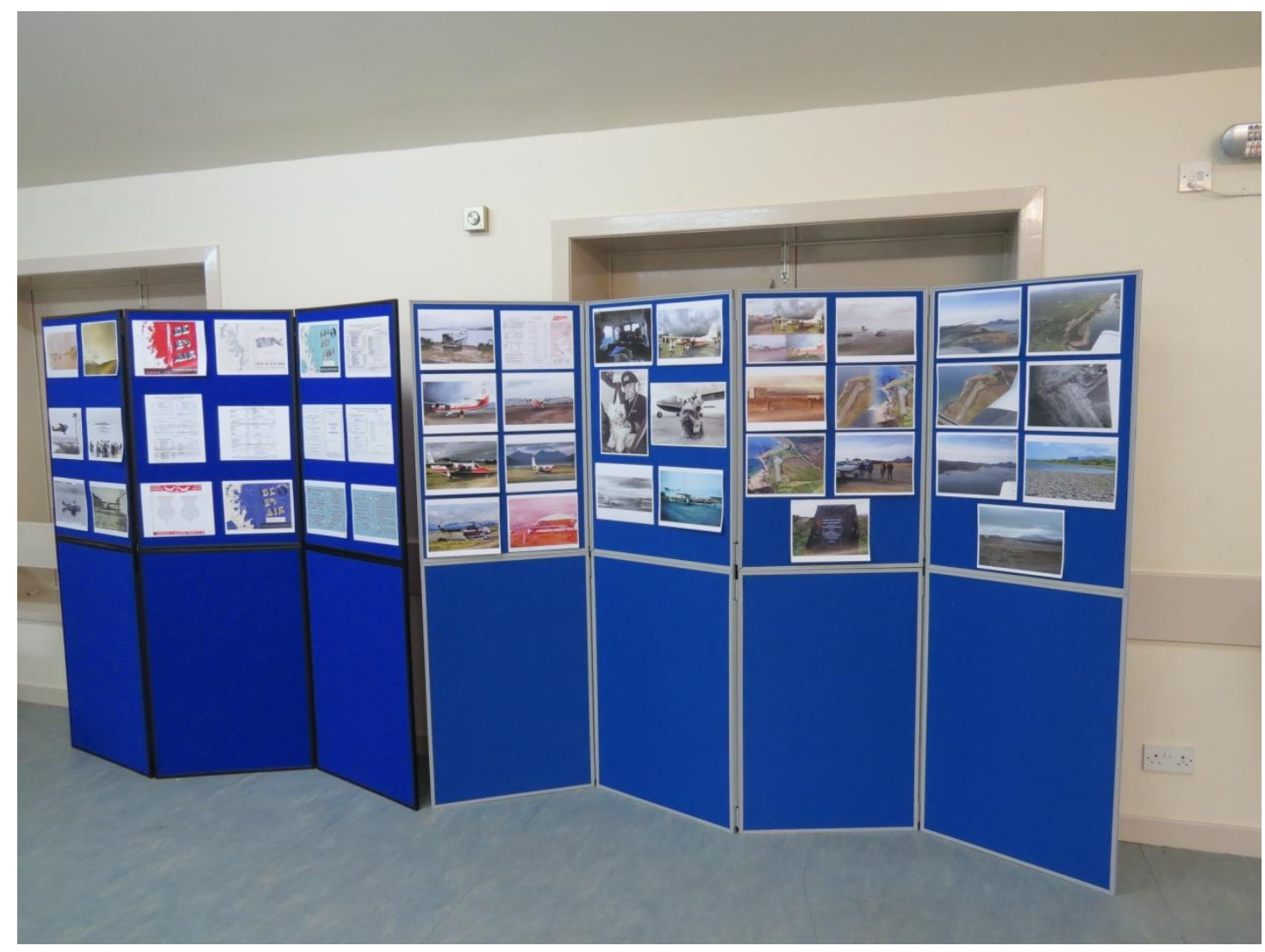

Figure 1: Photo exhibition at Broadford Village Hall, Isle of Skye, August 2016 


\begin{tabular}{|l|c|c|c|c|}
\hline \multicolumn{1}{|c|}{ Table 1: Number of participants in the three Scottish island communities } \\
\hline $\begin{array}{c}\text { Airport/ } \\
\text { Community }\end{array}$ & $\begin{array}{c}\text { People } \\
\text { engaged at } \\
\text { exhibitions }\end{array}$ & Interviewees & $\begin{array}{c}\text { Focus } \\
\text { group } \\
\text { participants }\end{array}$ & Totals \\
\hline Kirkwall Airport & 108 & 5 & 5 & 118 \\
\hline Benbecula Airport & 96 & 1 & - & 97 \\
\hline Isle of Skye & 75 & 3 & - & 78 \\
\hline Totals & $\mathbf{2 7 9}$ & $\mathbf{9}$ & $\mathbf{5}$ & $\mathbf{2 9 3}$ \\
\hline
\end{tabular}

